\title{
Emerging Market Demand and the Changing Dynamics of the Price of Gold
}

\author{
Yiling Zhang ${ }^{1} \&$ David Rakowski ${ }^{1}$ \\ ${ }^{1}$ Department of Finance and Real Estate, University of Texas at Arlington, Arlington, USA \\ Correspondence: Yiling Zhang, Department of Finance and Real Estate, University of Texas at Arlington, \\ Arlington, TX, 76013, USA. Tel: 1-817-272-1007. E-mail: yiling.zhang@mavs.uta.edu
}

Received: March 26, 2015

Accepted: June 1, 2015

Online Published: June 25, 2015

doi:10.5539/ijef.v7n7p56

URL: http://dx.doi.org/10.5539/ijef.v7n7p56

\begin{abstract}
Empirical research on the dynamics of the US dollar price of gold has largely focused on the macroeconomic influence of developed economies and gold's role as a safe haven during times of market turmoil. However, the economies of several emerging markets now account for a substantial fraction of global gold holdings, and these holdings are not necessarily correlated with financial market uncertainty in developed markets. This paper compares two extensions to a popular econometric model of the US dollar gold price. We do so by incorporating the consumer holdings of gold from the largest emerging markets and comparing the effectiveness of our model over time to one that incorporates a measure of volatility in US financial markets (the VIX index). Our results indicate that emerging market consumer demand has a significant and growing impact on the relationship between USD exchange rates and the price of gold, and that this relationship has a stronger influence than does the level of uncertainty in US financial markets.
\end{abstract}

Keywords: gold, APGARCH, exchange rates, VIX, emerging market consumer demand

\section{Gold Prices and the Value of the US Dollar}

Gold is a unique asset that has received relatively less attention from academic researchers than other financial assets, such as equities, currencies, and fixed-income securities. Gold serves several traditional financial purposes, acting both as a store of value and a means of exchange. Unlike other financial assets, gold also serves practical purposes both for industry and as jewelry. Although gold was the single most important financial asset in most economies throughout most of recorded history, the transition to fiat monetary systems in the twentieth century has relegated gold to a second-tier status in terms of attention from researchers and policy makers. This is despite the important role that gold continues to play for both retail investors and central banks.

For the past several decades, gold has been priced chiefly in US dollars. Therefore, changes in the price of gold may reflect the relative strength of the US dollar as much as any changes in the demand or supply of gold. The non-financial uses of gold, along with its unprecedented history as a store of value, cause many investors to view it as a hedge against financial uncertainty. This should cause the gold price to be negatively correlated with the value of the US dollar. While evidence on gold's ability to hedge against financial uncertainty is mixed, there exists convincing evidence of gold's negative correlation with the US dollar during the 1984-2003 time period (Tully \& Lucey, 2007; hereafter referred to TL).

TL provide a useful model with which to evaluate gold prices during the last two decades of the twentieth century. However, several features of the global economy have been evolving since the time frame of their study, which ended in 2003. First, the behavior of gold as an "anti-dollar" may have changed because the US dollar (or at least US-dollar-denominated assets such as US Treasury bonds) increasingly act as safe havens during times of global financial uncertainty, as was especially evident during the financial crises of 2006-2009. Second, demand for gold has increasingly come from the exogenous actions of emerging markets, whose participants are motivated by domestic economic and political considerations that are independent of the macroeconomic conditions of the developed economies.

Our analysis expands existing studies in several ways. First, we update and examine the evolving validity of the popular Asymmetric Power Generalized Auto-regressive Conditional Heteroskedasticity (APGARCH) econometric model of TL, which is developed from the methods of Ding, Granger, and Engle (1993). We then 
evaluate the importance of emerging market consumer demand relative to another popular variable used to explain the price of gold, the VIX measure of financial market uncertainty. Our analysis allows us to judge the importance of each variable in explaining the joint relationship between gold and US dollar exchange rates, as well as how these relationships have changed over time.

Our results illustrate several important facts about the dynamic relationship between gold prices and US dollar exchange rates. First, the fit of the TL model has degraded over time, especially in the post-2003 sample period. Second, emerging market demand has an important influence on gold prices. Including emerging market demand leads to a substantially better model fit and is significant in explaining the link between gold and the US dollar exchange rate. Third, the significance of emerging market consumer demand is a recent phenomenon, whose influence has strengthened over time. Fourth, in the context of the TL model, financial market uncertainty is insignificant in explaining the price of gold and including it does not substantially improve model fit or explain the joint relationship between gold and US dollar exchange rates. Our analysis provides a demonstration of the extent to which once-accurate economic models are constantly in need of revision in order to maintain their usefulness in an ever-changing economic environment.

The paper is organized as follows. Section 2 discusses the existing research on the dynamics of exchange rates and gold pricing, emerging market demand for gold, and the potential links between market uncertainty and gold prices. Section 3 describes the APGARCH model of TL that we replicate and expand. Section 4 discusses the results of our analysis, while Section 5 offers conclusions and implications.

\section{Research on Gold Pricing, Exchange Rates, Consumer Demand, and Market Uncertainty}

Existing research on the dynamic relationship between gold prices and exchange rates have identified four distinct sets of variables that drive this relationship. The first set concerns shocks to macroeconomic variables, such as unexpected US money supply changes (Tandon \& Urich, 1987) and news about US budget deficits (Kitchen, 1996). A second stream of work models the gold price movement relative to interest rates. For instance, Koutsoyiannis (1983) and Fortune (1987) report there is a significant relationship between the gold price and U.S. short term interest rates. Diba and Grossman (1984) estimate the correlation between the time series properties of gold prices and interest rates.

The third set captures the extent to which gold acts as a safe haven and hedge against economic crises, uncertainty, or inflation. Sjaastad and Scacciavillani (1996) examine how gold stores value in a crisis period, while Baur and Lucey (2010) show that gold serves as a short-term safe haven for stocks. Cohen and Qadan (2010), Sari, Hammoudeh, and Soytas (2011), Qadan and Yagil (2012), Hood and Malik (2013), Padungsaksawasdi and Daigler (2014), and Miyazaki and Hamori (2013) model the relationship between gold prices and the VIX measure of volatility in US financial markets. They provide mixed evidence as to the usefulness of using the VIX measure of uncertainty in explaining changes in the price of gold.

The fourth perspective interprets the gold price movement as a function of U.S. dollar exchange rates. Capie, Mills, and Wood (2005), Sari, Hammoudeh, and Soytas (2011), and Sari, Hammoudeh, and Soytas (2010) examine gold's hedging role against the U.S. dollar. Because gold prices are predominantly quoted in US dollars, any analysis of the price of gold necessarily involves jointly modeling the value of the US dollar. Consistent with this, Kaufman and Winters (1989) and Ghosh et al. (2004) found that changes in the dollar exchange rate had a significant impact on the price of gold.

One variable that has not received much attention in the published literature is the role of emerging market demand on the price of gold. Anecdotal evidence has suggested that demand for jewelry on the part of Indian consumers or for reserves by the People's Bank of China could mark substantial shifts in worldwide demand and holdings of gold (Clarke \& Li, 2014). However, these variables have not been evaluated in the context of formal empirical models.

It is also useful to note that published studies generally do not provide a simple analysis between gold and a single explanatory variable. All published studies include some multivariate joint analysis of the gold price, usually involving several of the categories of variables mentioned above, incorporating exchange rates, interest rates, and/or financial market measures. Our analysis evaluates the relative effectiveness of macroeconomic and risk-based measures in the joint modeling of gold prices and exchange rates.

\section{APGARCH Modeling of the Gold Price}

TL explore a wide variety of time-series models of the dynamic relationship between the price of gold and the value of the US dollar. They identify the APGARCH model as being appropriate for jointly modeling the price of gold and the value of the US dollar. The APGARCH formulation allows for effective modeling of the periods of 
volatility-clustering over time that are a feature of the price of gold.

Our APGARCH model(s) take the following form:

$$
G O L D_{t}=c+\sum \beta_{i} G O L D_{t-i}+\sum \gamma_{i} e_{t-i}+\sum \rho_{i} X+e_{t}
$$

And,

$$
\sigma_{t}^{d}=c+\sum_{j=1}^{q} \beta \sigma_{t-j}^{d}+\sum_{i=1}^{p} \vartheta_{i}\left(\left|e_{t-i}\right|+\lambda e_{t-i}\right)^{d}+\sum \rho_{i} X+\xi_{t}
$$

Where $G O L D_{t}$ represents natural log difference between the quarterly cash gold price from time $\mathrm{t}-1$ to time $\mathrm{t}$ and $\sigma_{t}{ }^{d}$ represents the variance of this process. X represents the set of macroeconomic explanatory variables that jointly describe the change in gold prices over time. These variables include US dollar and UK pound exchange rates, emerging market consumer demand, market uncertainty, and control variables.

\section{Empirical Analysis}

We implement our tests with data from Datastream over the time period from 1984 until 2013. Our dependent variables of interest are $G O L D$, the monthly gold bullion cash price in US dollars per troy ounce (Note 1), the USD dollar effective exchange rate (Dollar), the UK Pound Sterling effective exchange rate (Pound). We also include the same control variables as TL: the FTSE 100 equity index (FTSE), the US 3-month T-Bill interest rate (TBill), and the UK consumer price index (UK CPI). A new data point that we collect and incorporate into the model is the sum of Indian and Chinese consumer demand for gold (EM Demand). EM Demand represents data codes CHCGTCDQP and INCGTCDQP from Datastream, originally sourced from Thomson Reuters GFMS, and measured by non-seasonally-adjusted gross volumes, in tons. We measure gold demand by volume rather than value because any price-based measure would be endogenous to our analysis. We also include the VIX index of financial market volatility $(V I X)$ as a proxy for market uncertainty. All variables are measured as the change in $\log$ value from period $t-1$ to $t$. Additional tests also interact time trend variables with VIX and EM Demand in order to examine how these two variables may have evolved over time in their ability to explain gold price dynamics. Table 1 provides descriptive statistics of our quarterly data. The values and characteristics of our data are comparable to those in other studies.

Figure 1 illustrates the cumulative values of our primary variables over our sample period. From Figure 1 it is apparent that the gold price has exhibited a long-term appreciation that dwarfs the growth rate of our other variables. EM Demand has experienced more moderate growth over the sample period.

Table 1. Descriptive statistics of quarterly data

\begin{tabular}{llllll}
\hline & Mean & Median & SD & High & Low \\
\hline Gold & 790.88 & 641.54 & 490.71 & 1736.97 & 262.40 \\
EM Demand & 315.66 & 282.73 & 129.30 & 761.90 & 162.50 \\
Tbill & $1.96 \%$ & $1.35 \%$ & $1.99 \%$ & $6.24 \%$ & $0.01 \%$ \\
FTSE & 5432.25 & 5584.29 & 814.06 & 6596.69 & 3771.46 \\
UK CPI & 92.77 & 90.52 & 9.46 & 111.06 & 80.69 \\
VIX & 21.34 & 18.74 & 8.25 & 45.45 & 11.40 \\
Dollar & 95.76 & 93.25 & 13.21 & 123.36 & 77.01 \\
Pound & 94.26 & 99.39 & 9.09 & 104.65 & 77.74 \\
\hline
\end{tabular}

Note. The table presents descriptive statistics on quarterly data collected from Datastream over the 2000-2013 sample period. Gold is the monthly gold bullion cash price in US dollars per troy ounce. VIX is the VIX index value and EM demand is the sum of Indian and Chinese consumer demand for gold. Dollar and Pound are the US Dollar and UK pound Sterling effective exchange rates. FTSE is the level of the FTSE index. TBill is US 3-month T-Bill yield and UK CPI is the UK consumer price index. 


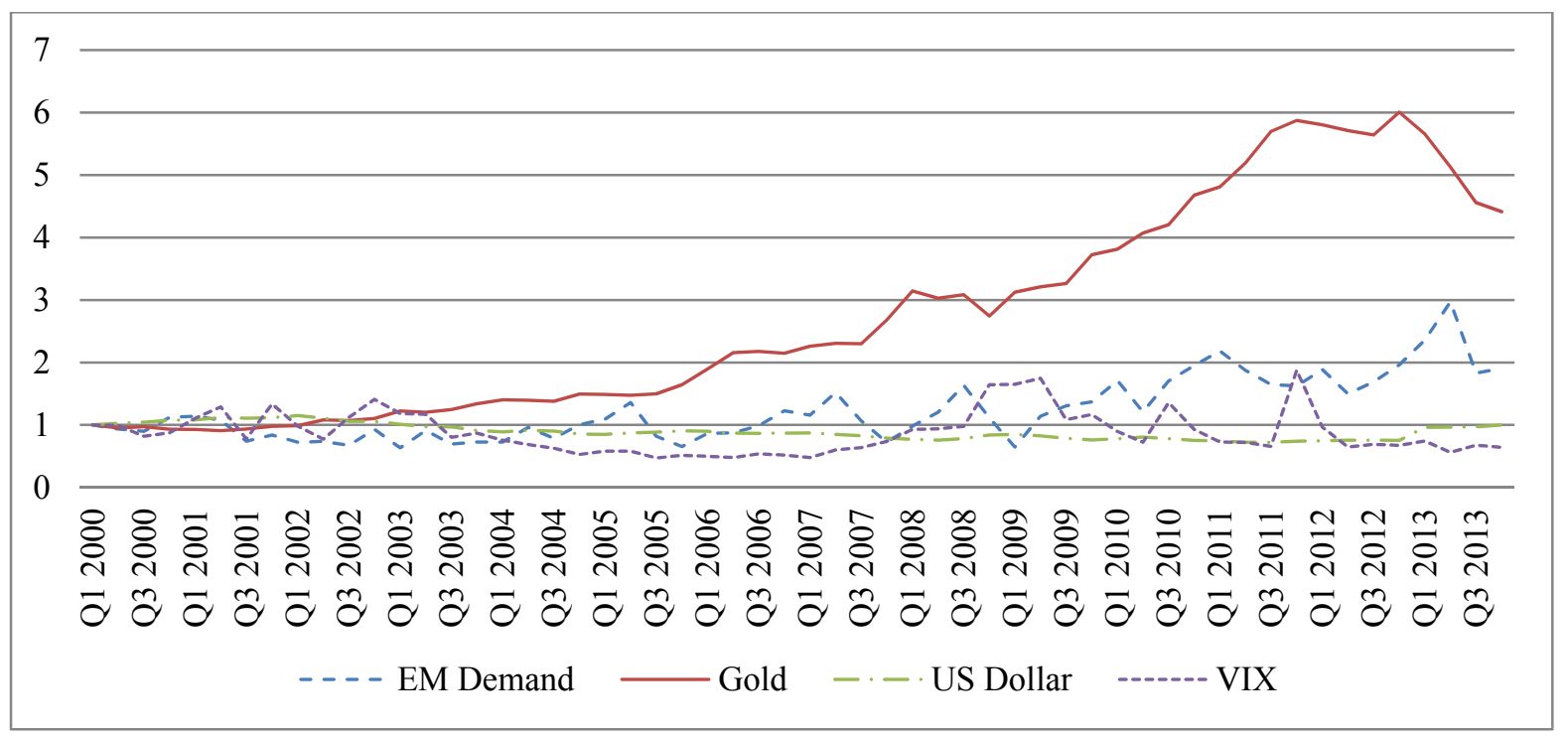

Figure 1. Cumulative values of quarterly variables

Note. The figure presents cumulative values of quarterly data collected from Datastream over the 2000-2013 sample period. Gold is the monthly gold bullion cash price in US dollars per troy ounce. VIX is the VIX index value and EM demand is the sum of Indian and Chinese consumer demand for gold. US dollar is the US Dollar effective exchange rate. Values are scaled such that the value for Q1:2000 equals 1.

Table 2 presents estimates from our APGARCH models over the original TL sample period of 1984-2001, our expanded period of 2001-2013, and the full sample period of 1984-2013. Our replication of TL does not overlap exactly with their sample period because our data start in 1984 . However, our results are very close to theirs over almost the same sample period. While coefficient estimates are similar in both sub-periods, the R-squared measure indicates that the model fit degrades substantially in the later time period, with a decrease from $7.58 \%$ to $-5.20 \%$. This indicates that new variables may be appropriate to update this model for the post-2001 sample period.

Table 2. APGARCH estimates of basic model over sample sub-periods

\begin{tabular}{|c|c|c|c|c|c|c|}
\hline & \multicolumn{2}{|c|}{$1984-2001$} & \multicolumn{2}{|c|}{$2001-2013$} & \multicolumn{2}{|c|}{$1984-2013$} \\
\hline Mean Equation & Coefficient & Standard Error & Coefficient & Standard Error & Coefficient & Standard Error \\
\hline Constant & -0.0003 & 0.0045 & 0.0076 & $0.0044 *$ & 0.0042 & 0.0027 \\
\hline FTSE & -0.0388 & 0.0738 & 0.0178 & 0.0942 & -0.0079 & 0.0459 \\
\hline DOLLAR & -0.6548 & $0.1811 * * *$ & -0.7038 & $0.0001 * * *$ & -0.5806 & $0.0906^{* * *}$ \\
\hline POUND & -0.1406 & 0.1784 & 0.1138 & 0.2372 & -0.0651 & 0.11092 \\
\hline$T B I L L$ & 0.0427 & 0.0715 & -0.0110 & 0.0131 & -0.0029 & 0.0101 \\
\hline$U K C P I$ & -0.4013 & 0.7511 & 1.8454 & 1.0193 & -0.2061 & 0.5161 \\
\hline Adjusted $\mathrm{R}^{2}$ & $7.58 \%$ & & $-5.20 \%$ & & $2.27 \%$ & \\
\hline Variance Equation & Coefficient & Standard Error & Coefficient & Standard Error & Coefficient & Standard Error \\
\hline CONSTANT & 0.0010 & 0.0035 & 0.0270 & 0.1027 & 0.0116 & 0.0261 \\
\hline THETA & 0.0022 & 0.0820 & 0.0422 & 0.0574 & 0.0941 & 0.0407 \\
\hline LAMBDA & 0.1077 & 14.3772 & -0.9967 & 0.1523 & -0.6366 & 0.3531 \\
\hline BETA & 0.5267 & 0.2708 & 0.8709 & 0.0807 & 0.7789 & 0.0577 \\
\hline FTSE & -0.0070 & 0.0198 & -0.0136 & 0.1167 & -0.1021 & 0.1475 \\
\hline DOLLAR & -0.0075 & 0.0265 & 0.3153 & 0.3506 & 0.0161 & 0.0616 \\
\hline POUND & 0.0065 & 0.0228 & -0.0064 & 0.2812 & 0.1286 & 0.2062 \\
\hline TBILL & 0.0027 & 0.0080 & -0.0385 & 0.0386 & -0.0155 & 0.0195 \\
\hline$U K C P I$ & -0.0267 & 0.0931 & 0.3152 & 1.5893 & 0.3036 & 0.4913 \\
\hline D & 1.9280 & 0.9964 & 0.4241 & 1.0928 & 0.7973 & 0.6863 \\
\hline
\end{tabular}

Note. This Table presents coefficient estimates and standard errors from the APGARCH models described in equations 1 and 2. The dependent variable, Gold, is the monthly gold bullion cash price in US dollars per troy ounce. The first two columns present results for the 1984-2001 period, columns 3-4 for the 2001-2013 period, and columns 5-6 for the full 1984-2013 period. Significance levels are indicated by $* * *$ for $1 \%$, ** for $5 \%$, and * for $10 \%$ levels. 
Estimates of our model that incorporate the $V I X$ measure of market uncertainty are presented in Table 3 . The $V I X$ variable is insignificant in explaining the price of gold. We also see no significant evidence of the power of VIX changing over our sample period, as the coefficient estimate on our time-trend interaction term is also insignificant. The adjusted R-squared measures of $10.75 \%$ and $12.94 \%$ indicate that these models provide little additional power to explain variation in gold prices beyond that of the base model presented in Table 2 . The weakness of VIX in explaining gold prices in the context of our model is in contrast to the results (using a different modeling approach) of Qadan and Yagil (2012).

Table 3. APGARCH estimates including VIX terms

\begin{tabular}{lllll}
\hline Mean Equation & Coefficient & Standard Error & Coefficient & Standard Error \\
\hline Constant & 0.0270 & $0.0106^{* *}$ & 0.0267 & $0.0124^{* *}$ \\
FTSE & 0.2578 & 0.1682 & 0.2211 & 0.2315 \\
DOLLAR & -0.5953 & $0.2667^{* *}$ & -0.5530 & $0.3112^{*}$ \\
POUND & -0.5058 & 0.3082 & -0.4061 & 0.4333 \\
TBILL & -0.0065 & 0.0272 & 0.0075 & 0.0194 \\
UKCPI & 0.1855 & 1.4266 & 0.1106 & 1.6149 \\
VIX & 0.0212 & 0.0391 & -0.0122 & 0.1126 \\
VIX* Time Trend & & & 0.0013 & 0.0028 \\
\hline Adjusted ${ }^{2}$ & $10.75 \%$ & & $12.94 \%$ & \\
\hline Variance Equation & Coefficient & Standard Error & Coefficient & Standard Error \\
\hline CONSTANT & 0.0021 & 0.0134 & 0.0022 & 0.0114 \\
THETA & 0.1028 & 0.4458 & 0.0826 & 0.2380 \\
LAMBDA & -0.6439 & 3.5141 & 0.0192 & 1.1660 \\
BETA & 0.4623 & 0.4169 & 0.4893 & 0.4915 \\
FTSE & 0.0019 & 0.0218 & 0.0027 & 0.0204 \\
DOLLAR & 0.0301 & 0.1770 & 0.0205 & 0.1020 \\
POUND & -0.0223 & 0.1337 & -0.0152 & 0.0890 \\
TBILL & -0.0016 & 0.0096 & -0.0009 & 0.0047 \\
UKCPI & -0.1078 & 0.6625 & -0.1160 & 0.5941 \\
VIX & 0.0034 & 0.0196 & 0.0026 & 0.0128 \\
VIX* Time Trend & & & 0.0000 & 0.0004 \\
D & 1.8991 & 2.1309 & 1.9115 & 1.6629 \\
\hline
\end{tabular}

Note. This Table presents coefficient estimates and standard errors from the APGARCH models described in equations 1 and 2. The dependent variable, Gold, is the quarterly gold bullion cash price in US dollars per troy ounce over the 2000 to 2013 sample period. The first two columns present results including a term for the VIX index. The third and fourth columns include both the VIX and the VIX interacted with a time trend variable. Significance levels are indicated by $* * *$ for $1 \%$, ** for $5 \%$, and $*$ for $10 \%$ levels.

Table 4 incorporates demand (EM Demand) from consumers in the emerging markets of India and China into our model. This variable is marginally significant in the first specification of our model and quite significant in the second specification. Interestingly, the coefficient takes a significant negative coefficient estimate, suggesting that increased holdings of gold by Indian and Chinese consumers are associated with a decrease in the price of gold. Although our tests do not probe the nature of causality, the results suggests that over a short-term horizon, emerging market consumers respond to decreases in the dollar price of gold by increasing their gold holdings, and not that increases in emerging market demand lead to short-term increases in the price of gold. The R-squared measures of $19.25 \%$ and $19.88 \%$ also indicate that models including this variable provide a much better fit that our base model from Table 2 or models incorporating the VIX measure, presented in Table 3 . The interaction of the time trend with EM Demand suggests that that most of the power of EM Demand in explaining the price of gold has come from the strengthening of this relationship over time. 
Table 4. APGARCH estimates including emerging market demand

\begin{tabular}{|c|c|c|c|c|}
\hline Mean Equation & Coefficient & Standard Error & Coefficient & Standard Error \\
\hline Constant & 0.2844 & $0.1464 *$ & 0.5659 & $0.2107 * * *$ \\
\hline FTSE & 0.2458 & $0.1206^{* *}$ & 0.2282 & $0.1185^{*}$ \\
\hline DOLLAR & -0.3174 & 0.2642 & -0.2953 & 0.2443 \\
\hline POUND & -0.3487 & 0.3056 & -0.4050 & 0.3846 \\
\hline TBILL & -0.0159 & 0.0200 & -0.0277 & 0.0310 \\
\hline$U K C P I$ & 0.6042 & 1.5573 & -0.1043 & 1.4674 \\
\hline EM Demand & -0.0466 & $0.0263 *$ & -0.1048 & $0.0411^{* *}$ \\
\hline EM Demand *Time Trend & & & 0.0003 & $0.0001^{*}$ \\
\hline Adjusted $\mathrm{R}^{2}$ & $19.25 \%$ & & $19.88 \%$ & \\
\hline Variance Equation & Coefficient & Standard Error & Coefficient & Standard Error \\
\hline CONSTANT & 0.0022 & 0.0308 & 0.0031 & 0.0244 \\
\hline THETA & 0.0276 & 0.2356 & 0.0829 & 0.2918 \\
\hline LAMBDA & -0.1171 & 3.7429 & 0.0391 & 0.9626 \\
\hline BETA & 0.4668 & 0.4159 & 0.5345 & 0.2697 \\
\hline FTSE & 0.0094 & 0.0981 & 0.0044 & 0.0252 \\
\hline DOLLAR & 0.0166 & 0.1646 & 0.0198 & 0.1209 \\
\hline POUND & -0.0244 & 0.2310 & -0.0330 & 0.1965 \\
\hline TBILL & -0.0032 & 0.0323 & -0.0023 & 0.0134 \\
\hline UKCPI & -0.0392 & 0.3811 & -0.0657 & 0.3832 \\
\hline EM Demand & -0.0001 & 0.0027 & -0.0004 & 0.0040 \\
\hline EM Demand* Time Trend & & & 0.0000 & 0.0000 \\
\hline $\mathrm{D}$ & 1.9131 & 3.6564 & 2.0095 & 2.0500 \\
\hline
\end{tabular}

Note. This Table presents coefficient estimates and standard errors from the APGARCH models described in equations 1 and 2. The dependent variable, Gold, is the quarterly gold bullion cash price in US dollars per troy ounce over the 2000 to 2013 sample period. The first two columns present results including a term for Emerging Market Consumer Demand (EM Demand) for gold. The third and fourth columns include both EM Demand and EM Demand interacted with a time trend variable. Significance levels are indicated by *** for $1 \%$, ** for $5 \%$, and $*$ for $10 \%$ levels.

During the third and fourth quarters of 2013, the Indian government instituted import restrictions on gold known as the "80:20 rule" (Christensen, 2014). The imposition of the 80:20 rule coincided with a sharp drop in US dollar gold prices and raises questions about how dependent our results are on this specific sub-period. Table 5 therefore reports our APGARCH model including EM Demand, but drops observations the last two quarters of 2013 when the 80:20 rule was in effect. The estimates reported in Table 5 remain very similar to those in Table 4. This indicates that the coefficient estimates reported in Table 4 describe a fairly persistent relationship between gold price and the value of the US dollar over recent years and is not merely driven by the extreme movement in emerging market demand for gold in the second half of 2013.

Table 5. APGARCH estimates including emerging market demand

\begin{tabular}{lllll}
\hline Mean Equation & Coefficient & Standard Error & Coefficient & Standard Error \\
\hline Constant & 0.2711 & $0.1317 * *$ & 0.5752 & $0.2122^{* * *}$ \\
FTSE & 0.2449 & $0.1108^{* *}$ & 0.2127 & 0.1585 \\
DOLLAR & -0.3013 & 0.2499 & -0.2660 & 0.2222 \\
POUND & -0.3794 & 0.3453 & -0.4623 & 0.3389 \\
TBILL & -0.0147 & 0.0186 & -0.0179 & 0.0250 \\
UKCPI & 0.6384 & 1.5719 & -0.1429 & 1.4589 \\
EM Demand & -0.0442 & $0.0237 *$ & -0.1073 & $0.0410^{* * *}$ \\
EM Demand ${ }^{*}$ Time Trend & & & 0.0003 & $0.0002^{*}$ \\
Adjusted R ${ }^{2}$ & $18.17 \%$ & & $21.35 \%$ & \\
\hline Variance Equation & Coefficient & Standard Error & Coefficient & Standard Error \\
\hline CONSTANT & 0.0022 & 0.0373 & 0.0036 & 0.0287 \\
THETA & 0.0422 & 0.2935 & 0.0710 & 0.2855 \\
LAMBDA & -0.1399 & 2.9575 & 0.0243 & 1.1355 \\
\hline
\end{tabular}




\begin{tabular}{lllll}
\hline BETA & 0.4597 & 0.4595 & 0.5434 & 0.3566 \\
FTSE & 0.0102 & 0.1314 & 0.0040 & 0.0250 \\
DOLLAR & 0.0173 & 0.2165 & 0.0194 & 0.1240 \\
POUND & -0.0251 & 0.3025 & -0.0313 & 0.1975 \\
TBILL & -0.0032 & 0.0407 & -0.0019 & 0.0113 \\
UKCPI & -0.0391 & 0.4704 & -0.0837 & 0.5345 \\
EM Demand & -0.0001 & 0.0031 & -0.0005 & 0.0046 \\
EM Demand* Time Trend & & & 0.0000 & 0.0000 \\
D & 1.9192 & 4.6744 & 2.0212 & 2.1820 \\
\hline
\end{tabular}

Note. This Table presents coefficient estimates and standard errors from the APGARCH models described in equations 1 and 2. The dependent variable, Gold, is the quarterly gold bullion cash price in US dollars per troy ounce over the sample period from first quarter 2000 to second quarter 2013. The first two columns present results including a term for Emerging Market Consumer Demand (EM Demand) for gold. The third and fourth columns include both EM Demand and EM Demand interacted with a time trend variable. Significance levels are indicated by $* * *$ for $1 \%, * *$ for $5 \%$, and $*$ for $10 \%$ levels.

\section{Conclusions and Future Directions}

Our analysis has shown that the APGARCH modeling approach of Tully and Lucey (2007) can be a useful starting point in understanding the evolving nature of how gold prices are determined by investors. A basic model of US dollar gold prices that worked well in the 1984-2001 period no longer remains as effective in more recent time periods. We explore the potential of using the $V I X$ measure of market uncertainty as a potentially useful variable to use in updating the TL model, but find that VIX has little power to explain gold prices in the context of this model. Instead, we find that the consumer demand from major emerging markets (India and China) is a much more useful variable to use in explaining gold price dynamics. Emerging market consumer demand is significant in explaining the US dollar gold price, it substantially improves the fit of our model, and has increased in importance over time.

Our approach illustrates how models must be continually updated in order to remain relevant in changing market conditions. In this analysis we have focused on the mean equations of the TL APGARCH model of the gold price. We have not focused on the variance component of the equation, and have not found any of our explanatory variables to be strongly related to volatility clustering of the gold price over time, or of how this relationship has changed in more recent periods. This would be a potentially useful area for further research and may help to explain why the Threshold GARCH (TARCH) modeling approach of Qadan and Yagil (2012) finds a much stronger association between $V I X$ movement and gold prices than our analysis does. A last point to consider would be to examine the nature of causality between emerging market consumer demand and gold prices. We have demonstrated a negative association between the two at quarterly horizons, but further work could identify if this represents the response of consumers to changing gold prices or pressure from consumer demand on international prices.

\section{References}

Baur, D. G., \& Lucey, B. M. (2010). Is gold a hedge or a safe haven? An analysis of stocks, bonds and gold. The Financial Review, 45, 217-229. http://dx.doi.org/10.1111/j.1540-6288.2010.00244.x

Capie, F., Mills, T. C., \& Wood, G. (2005). Gold as a hedge against the dollar. International Financial Markets, Instreuments and Money, 15, 343-352. http://dx.doi.org/10.1016/j.intfin.2004.07.002

Christensen, N. (2014). India drops 80: 20 Gold Import Restrictions. Forbes. Retrieved from http://www.forbes.com/sites/kitconews/2014/11/28/india-drops-8020-gold-import-restrictions/

Clarke, L., \& Li, Y. (2014). China overtakes India as Top Gold Consumer. The Wall Street Journal. Retrieved from http://www.wsj.com/articles/SB10001424052702304675504579389261432501856

Diba, B., \& Grossman, H. (1984). Rational bubbles in the price of gold. NBER Working Paper: 1300. National Bureau of Economic Research, Cambridge, MA. http://dx.doi.org/10.3386/w1300

Fortune, J. N. (1987). The inflation rate of the price of gold, expected prices and interest rates. Journal of Macroeconomics, 9, 71-82. http://dx.doi.org/10.1016/S0164-0704(87)80007-1

Ghosh, D., Levin, E. J., Macmillan, P., \& Wright, R. E. (2004). Gold as an inflation hedge. Studies in Economics and Finance, 22(1), 1-25. http://dx.doi.org/10.1108/eb043380

Kaufmann, T., \& Winters, R. (1989). The price of gold: A simple model. Resource Policy, 19, 309-318. 
http://dx.doi.org/10.1016/0301-4207(89)90004-4

Kitchen, J. (1996). Domestic and international financial market responses to federal deficit announcements. Journal of International Money and Finance, $239-254$. http://dx.doi.org/10.1016/0261-5606(96)00003-4

Koutsoyiannis, A. (1983). A short-run pricing model of a speculative asset tested with data from the gold bullion market. Applied Economics, 15, 563-582. http://dx.doi.org/10.1080/00036848300000037

Qadan, M., \& Yagil, J. (2012). Fear sentiment and gold price: Testing causality in-mean and in-variance. Applied Economics Letters, 19, 363-366. http://dx.doi.org/10.1080/13504851.2011.579053

Sjaastad, L. A., \& Scacciaviliani, F. (1996). The price of gold and the exchange rates. Journal of International Money and Finance, 15, 879-897. http://dx.doi.org/10.1016/S0261-5606(96)00045-9

Tandon, K., \& Urich, T. (1987). International market response to announcements of US macroeconomic data. Journal of International Money Finance, 6, 71-84. http://dx.doi.org/10.1016/0261-5606(87)90014-3

Tully, E., \& Lucey, B. M. (2007). A Power GARCH examination of the gold market. Research in International Business and Finance, 21, 316-325. http://dx.doi.org/10.1016/j.ribaf.2006.07.001

\section{Note}

Note 1. As with TL, we also run all models with the COMEX gold futures price. The results are similar to those presented for cash prices and are therefore not reported.

\section{Copyrights}

Copyright for this article is retained by the author(s), with first publication rights granted to the journal.

This is an open-access article distributed under the terms and conditions of the Creative Commons Attribution license (http://creativecommons.org/licenses/by/3.0/). 